\title{
Input Processing of Turkish Learners of English from Beginner and Advanced Level of Proficiency
}

\author{
Eda Duruk \\ Pamukkale University, Turkey \\ easlan@pau.edu.tr
}

\author{
Fatma Hülya Özcan \\ Anadolu University, Turkey \\ fozcan@anadolu.edu.tr
}

\begin{abstract}
English L1 acquirers learning Romance Languages have been claimed to process the first noun or pronoun of a sentence as the agent. However, because most of the evidence is based on learners with English as an L1, it is not clearly known whether this is due to a universal strategy or is a result of L1 transfer. According to one model of input processing (VanPatten, 2007), L2 learners would initially assign agent position to the first noun and object position to the second noun (First Noun Principle) or it might be that the L1 parser is transferred into the L2 input processing procedures (L1 Transfer Principle). The present study aims to address whether the L1 parsing procedures are transferred or whether there is a universal First Noun Principle. L1 Turkish speakers learning English as an L2 enrolled in beginning $(n=48)$ and advanced $(n=48)$ English classes were asked to interpret English sentences which included contextual cues or neutral contexts preceding the target clause. All participants completed two tasks: an impromptu discussion and a data-elicitation task. In order to analyze the data, the frequency of the items was calculated and chi-square test was applied for each independent variable. The results indicated that learners from beginner proficiency level interpreted subjects differently in different input conditions whereas the subject identification was not different for learners from advanced level of proficiency.
\end{abstract}

Keywords: First noun principle, input processing, age, word order. 


\section{Introduction}

Second language acquisition is an independent nonapplied discipline whose aim is to explain how second languages are learned (Gass \& Schachter, 1989). It has been claimed that the goal of second language acquisition research is to understand how a linguistic system develops in a learner's head. A researcher in second language acquisition identifies a phenomenon, examines the variables involved, conducts research (or theorizes about the phenomenon), and eventually draws a conclusion about the phenomenon. In this view, second language acquisition is divorced of pedagogical interests. VanPatten noted that "pedagogy must reflect an understanding of (a) theory of second language acquisition and pedagogical principles and practices should be firmly grounded in theory and research" (1996, p.1). On the other hand, other researchers (i.e.; Lee, 2003) could argue that second language acquisition research is as important as the pedagogical issues

motivating it. According to them, the matters that directly affect teachers and learners in classrooms should be researched. Research and theorizing should be at the service of pedagogy and not divorced from it.

Processing instruction, which links second language acquisition theory and research, is a type of grammar instruction whose aim is to affect the ways in which learners attend to input data. It is input-based and constant with both general second language acquisition theory and communicative language teaching. It was first described in VanPatten (1984) and has since been described, discussed and researched in a number of studies (Cadierno, 1992,1995; Cheng, 1995; Lee \& VanPatten, 1995; VanPatten, 1993; VanPatten \& Cadierno, 1993; VanPatten \& Oikkenon, 1996; VanPatten \& Sanz, 1995).

Bearing these issues in mind, native speakers of Turkish acquiring English as a foreign language (EFL) rely on word order to assign the grammatical roles of subject and object to words in a 
sentence like speakers of any language would do. One of the accounts for this tendency is the psycholinguistic strategy which causes L2 learners to assign the roles of subject or agent to the first noun encountered in a target sentence (Lee, 1987; LoCoco, 1987; VanPatten, 1984; VanPatten and Houston, 1998). This process can yield non-nativelike interpretations and delay the acquisition of object pronouns because of the variable word order characteristic of Turkish. For example, both of the following Turkish sentences are grammatical, having the same meaning, "Ayşe bought her the book":
(1) Ayșe
$\underline{\text { kitab1 }}$
ona
$\underline{\text { ald } 1}$

Ayşe-Subj IO-book+ case marker DO-pronoun+case marker+female verb-past tense marker

(2) ona $\underline{\text { kitab1 }}$

Ayșe

$\underline{\text { ald } 1}$

DO-pronoun+case marker+female IO-book+ case marker

Ayşe-Subj verb-past tense marker

Any language learner whose native language is not Turkish can misinterpret (2) as 'She bought the book' by assigning the grammatical role of subject to the direct object pronoun ona 'her' because of the psycholinguistic strategy discussed earlier. The present study aims to investigate the Contextual Constraint Principle which predicts that learners can rely less on the First Noun Principle if preceding context constrains the possible interpretation of a clause or sentence.

\section{Input and Processing Instruction}

There is a consensus among second language researchers that input is an essential component of second language acquisition. Learners use input in order to construct a mental representation of the grammar that they are acquiring. However, there is also consensus that not all of input is attended to. Learners filter the input, processing it so that only a reduced subset of the inputcalled intake - is made available for accommodation by the developing system (Krashen, 1985; VanPatten, 1996). Although different researchers hold different perspectives on second language 
acquisition, all confirm that meaningful input is essential to second language acquisition (Krashen, 1985; Larsen-Freeman \& Long, 1991; VanPatten, 1996). According to them learners must be exposed to samples of language that are used to communicate information.

That assumption led researchers to reanalyze traditional approaches to grammar instruction. Therefore, some researchers (e.g., Long, 1983; VanPatten, 1996) questioned the meaning-bearing input in output practice by depending on the fact that meaning-bearing input is one of the essential building blocks of acquisition. They supported processing instruction, which is an input-based approach to focus on form. In such activities, learners are pushed to attend to properties of the language during which they hear or see language that expresses some meaning. These activities contain purposefully manipulated sentences and discourse that carry meaning.

\section{Input Processing}

VanPatten (1996) states that, because instruction can make certain grammatical forms more salient in the input, grammar instruction has a positive role in the acquisition process. His model includes three stages; input and intake, intake and the developing system, and the developing system and output.

VanPatten claims that during input processing, which covers the first stage- input and intake, learners process input as they attempt to comprehend the message carried in it and use the input to make form-meaning connections. During that process they filter the input, reducing it and having a new entity called 'intake'. Next stage covers the way learners incorporate a grammatical form or structure into the mental picture of the language they are creating. Moreover, it includes the way in which the incorporation of a form or structure can cause a ripple effect and make other things change without the learner knowing (VanPatten, 2003). The final stage is responsible for language production. 
This model includes principles interacting in complex ways in working memory (based on VanPatten, 2007):

P1. The Primacy of Content Words Principle: Learners process content words in the input before anything else.

a. The Lexical Preference Principle: Learners will process lexical items for meaning before grammatical forms when both encode the same semantic information.

a. (Revised) Lexical Preference Principle: If grammatical forms express a meaning that can also be encoded lexically (i.e., that grammatical marker is redundant), then learners will not initially process those grammatical forms until they have lexical forms to which they can match them.

b. The Preference for Nonredundancy Principle: Learners are more likely to process nonredundant meaningful grammatical markers before they process redundant meaningful markers.

c. The Meaning before Nonmeaning Principle: Learners are more likely to process meaningful grammatical markers before nonmeaningful grammatical markers.

P2. The First Noun Principle: Learners tend to process the first noun or pronoun they encounter in a sentence as the subject.

a. The Event Probability Principle: Learners may rely on event probabilities, where possible, instead of the First Noun Principle to interpret sentences.

b. The Lexical Semantics Principle: Learners may rely on lexical semantics, where possible, instead of the First Noun Principle (or an Ll parsing procedure) to interpret sentences.

c. The Contextual Constraint Principle: Learners may rely less on the First Noun Principle (or Ll transfer) if preceding context constrains the possible interpretation of a clause or sentence.

P3. The Sentence Location Principle: Learners tend to process items in sentence initial position before those in final position and those in medial position. 
The first principle is concerned with the processing of morphological form as well as functional categories like articles. The third principle suggests that sentence initial and sentence final positions are cognitively more salient than other constituents in a sentence.

The second principle, the third sub-principle of which is the concern of the present study, deals with word order. Research on L2 input processing demonstrated that context may affect how learners parse sentences. VanPatten (2007) gives the following two sentences as examples:

(4a) John is in the hospital because Mary attacked him.

(4b) John told his friends that Mary attacked him.

In Spanish, the embedded clause can either be SOV (Maria lo ataco) or OVS (lo ataco Maria). If the First Noun Principle was conducted, the OVS structure could be misinterpreted as "he attacked Mary." However, if the preceding context is "John is in the hospital" a misinterpretation is less likely because why would John be in the hospital if he attacked Mary? Therefore, one interprets that he's in the hospital as the result of an injury, so Mary must have attacked him. If the preceding context is a neutral as in "John told his friends" there is nothing to constrain interpretation of the clause that follows it: John could equally tell his friends that he attacked Mary or that Mary attacked him. Thus, the effects of context form 'The Contextual Constraint Principle'.

\section{Empirical Studies and the Hypotheses tested}

Different studies with different languages have been studied so far. VanPatten and Cadierno (1993) tried to change the learner's dependence on the first-noun strategy when processing input containing Spanish clitic object pronouns. Spanish, having flexible word order, allow different structure possibilities such as SVO, SOV, OVS, and OV. The subject can precede or follow the 
verb. By using the first-noun strategy, English speakers can conclude that the first noun or pronoun is the subject of the sentence. This makes them misinterpret the direct object as the subject. In another study, VanPatten and Sanz (1995) used an interpretation task, a sentence-level task, a structured question-answer task, and a video narration task to compare an input processing group with a control group. They found that the former group significantly improved on the interpretation task, while the latter one didn't. The input processing group also improved their accuracy on the written tasks and on the sentence completion test. However, on the oral video narration task, no significant difference was found.

Lots of different studies have been conducted following these studies. Some aimed to replicate the study of VanPatten and Cadierno (1993) and found two main problems about internal validity: 1. different type and amount of explicit grammar instruction, and 2. difference in the type of practice (DeKeyser \& Sokalski, 1996).

Cantürk (2001) also administered interpretation and production tasks to the input processing group and traditional instruction group. This study suggested that positive effects of processing instruction are durable on both interpretation and production tasks. However, there was no significant difference between the two instruction groups.

Finally, Lee (2003) conducted a research on the acquisition of Spanish object pronouns and asserted that the default processing strategy based on word order is pervasive into intermediate levels of learning and is detrimental to the acquisition of that feature of the language. His suggestions implied that the processing of word order is closely related to certain proficiency level. The present study differs from the previous ones in that it limits its scope to the Contextual Constraint Principle discussed earlier. The principle predicts that if there are some preceding 
contextual cues, misinterpretation is less likely. Thus, the hypotheses tested in the present study are formulated as follows:

$\mathrm{H}_{1}$ : Contextual cues preceding the target clause will help L2 learners interpret most of the subjects in a set of sentences correctly.

$\mathrm{H}_{2}$ : L2 learners will misinterpret most of the subjects in a set of sentences when the clause preceding the target one is neutral in terms of its context.

\section{Method}

\section{Participants}

Depending on convenience sampling, learners from two different beginner $(n=48)$ and advanced $(n=48)$ English classes participated in the current study as part of their regular class period. Their ages range from 18 to 21 . They were identified as beginner or advanced level learners of English after the implementation of the placement exam. The exam tested all language skills and the proficiency level of the learners was decided according to their scores. All participants $(n=96)$ were native speakers of Turkish. There were no heritage speakers of English who participated. All were enrolled in an intensive English course at the university level intended for individuals who had three years or more of high school English.

Table 1

The distribution of the participants in the study

\begin{tabular}{lcc}
\hline Total Number: 96 & Group A & Group B \\
\hline Beginner Level & 24 & 24 \\
Advanced Level & 24 & 24
\end{tabular}

\section{Data Collection}

Participation in the present study was voluntary. Each of the two different classes was further divided into two main groups. The two groups will be referred to as Group A and Group B. Each group consisted of an equal number of participants $(\mathrm{N}=24)$. Table 1 shows the groups. 
All participants, regardless of which group they were in, received the same data-elicitation procedures. The only difference between the two groups was that Group A received input consisting of English sentences with contextual cues preceding the target clause, whereas Group B received input consisting of English sentences containing neutral preceding context (the difference in input between the two groups will be further explained below).

All participants completed the following two tasks: (1) an impromptu discussion, in English, regarding the characters from the popular Turkish TV series, Yaprak Dökümü; and (2) a dataelicitation task.

\section{Impromptu Discussion}

The impromptu discussion regarding Yaprak Dökümü (a Turkish TV series) was intended to activate the schemata, i.e. topic familiarity, of the participants regarding the different characters in the story. Yaprak Dökümü was chosen because of its popularity and longevity within Turkish culture, and assumed that everyone would be familiar with it. The discussion was conducted in English in order to ensure its comprehensibility. During the discussion in each of the groups, participants had to name as many characters as possible from the story, in addition to as many adjectives as possible describing each character. The researcher wrote the names of the characters, accompanied by their respective adjectives, on the board. When the discussion ended, the researcher erased the information before going on to the following task. The ultimate objective of the impromptu discussion was to ensure that target sentences in the data-elicitation task would be reliable which were coded for + topic familiarity.

\section{Data-elicitation task}

Data elicitation began after all participants had completed the impromptu discussion. First, each of the verbs to be used in the task was reflected to the learners by means of a projector, in order to 
ensure there would be no unfamiliar vocabulary in the task. When learners, especially at the beginner level, encountered unfamiliar vocabulary, visual materials helped the researcher to make the learners be familiarized with the target vocabulary. Second, a projector was used to provide each group with different sets of input sentences, one sentence at a time. Participants were instructed to read the sentence and then respond to the corresponding prompt on the answer sheet. Each sentence was projected on the overhead for six seconds (VanPatten, B. \& Houston, T., 1998) before moving on to the next sentence. The researcher kept time using a watch. The target sentences for each group were as follows; the set of input for each group included ten sentences, each of which consisted of scenarios regarding characters from Yaprak Dökümü. Group A received the set of English sentences with contextual cues preceding the target clause, while Group B received the same amount of input consisting of English sentences containing neutral preceding context.

Utilizing the methods of VanPatten and Houston (1998), a fill-in-the-blank procedure (see Appendix A for the target input sentences) was adapted. The aim of the task was to investigate whether Turkish learners of English would process the first noun directly as the subject as proposed by the First Noun Principle mentioned earlier. An example of a target input sentence is shown in (1a), and the corresponding prompt on the participant's answer sheet in (1b):

(1a) “Şevket doesn’t improve himself in his job, but Sedef does, and at times she criticizes him."

(1b) criticizes

Each of the input sentences in the present study consisted of transitive verbs, i.e. every verb required a subject and an object. All participants received the same answer sheet. Thus, Group A and Group B both completed the fill-in-the-blank task regarding the Turkish series, Yaprak Dökümü. All participants were encouraged to use the proper names given in the task. 


\section{Data Analysis}

If the learner interpreted the target subject accurately, (s)he got 1 point; if (s)he did not, no point was given. Therefore, if a student fills in all 10 blanks correctly, s/he gets 10 points overall. When each group is considered, the highest score for one item was 48 (48 participants $\times 1$ point). Items that were not responded to by the participant, or, that had ambiguous responses, were excluded from data analysis. For the fill-in-the-blank task, if the learner responded with English pronouns, such as She criticizes him, instead of full noun phrases, their response was not included in the analysis, because other similar responses, such as $H e$ criticizes him, would yield an ambiguous interpretation of the data. As mentioned earlier, participants were told to use the proper names provided in the target sentences. In order to analyze the data, the frequency of the items was calculated and chi-square test was applied for each independent variable. The dependent variable of the study is the correct subject interpretation; whereas, the independent variables are the proficiency level and the two different input conditions.

\section{Results and Discussion}

Table 2

Overall and group-specific frequency of correct subject interpretation

\begin{tabular}{lcccc}
\hline Groups & \multicolumn{2}{c}{ Group A } & \multicolumn{2}{c}{ Group B } \\
\hline & Percentage / Raw scores & Percentage / Raw scores \\
Beginner Level & $83,3 \%$ & 20 & $50 \%$ & 12 \\
Advanced Level & $100 \%$ & 24 & $100 \%$ & 24 \\
Total Raw Scores: 80 (out of 96) & $91,6 \%$ & 44 & $75 \%$ & 36 \\
\multicolumn{1}{c}{ Percentage: } & $83,3 \%$ & & & \\
\hline
\end{tabular}

As can be seen in Table 2, the percentages of beginner level students within each group differ from each other, group A and group B having 83, 3\% and 50\%, respectively. Thus, each group performed 
differently under each input condition. Hence, for these students, contextual cues that preceded the target clause yielded results that were different than the condition in which neutral contexts were provided.

The fact that Group A (with contextual cues) performed differently when compared to Group B (with neutral context) under each input condition indicated that the existence of a contextual cue in a sentence has an effect on how the participants from lower proficiency level interpret the subject while processing the target sentences. Thus, it can be concluded that the strong effects of the first noun principle suggested by VanPatten (1998) can be overridden by the context. When the overall percentage of beginner level students is taken into account, the results revealed that they identified more than half of the subjects in the target clauses correctly $(66,6 \%)$. This high percentage was obtained because contextual cues in Group A increased the percentage.

Table 3

Chi square tests for each independent variable across both groups of participants

\begin{tabular}{lll} 
& Sig. & $d f$ \\
\hline *Beginner prof. level - Input condition & .000 & 1 \\
Advanced prof. level - Input condition & .411 & 1 \\
\hline
\end{tabular}

* Achieved level of significance $(p<.001)$

The chi-square analysis, indicated in Table 3, revealed that, of the two different proficiency levels and the two different input conditions, beginner proficiency level within the input conditions had a significant main effect on the dependent variable $(p<.001)$. The participants from beginner proficiency level had higher percentage of correct subject interpretation when contextual cues preceded the target clause. On the other hand, when neutral contexts were provided the percentage of correct identification decreased. 
With respect to the participants from advanced proficiency level, contextual cues that preceded the target clause yielded results that were not significantly different than those of the neutral contexts. Thus, those participants in Group A (with contextual cues) performed the same as the ones in Group B (with neutral contexts) under each of the experimental conditions, indicating that the presence or absence of contextual cues in the sentence had no effect on how the two groups behaved under equal conditions.

Depending on the results of beginner level students, the first hypothesis- contextual cues preceding the target clause will help L2 learners interpret most of the subject correctly, is confirmed (83, 3\%). Similarly, the second hypothesis- L2 learners will misinterpret most of the subject when the clause preceding the target one is neutral in terms of its context, is partially verified because half of the responses of Group B were not accurate (50\%).

The significant difference between the two groups can be because of the fact that students from lower proficiency level try to grasp every detail, in a much effortful way to understand a sentence. Given that, if such students are provided with contextual cues, it is highly probable that they will also pay attention to these cues in order to process the input they have received.

With respect to advanced level students, it can be seen in Table 2 that the frequencies of each group are just the same. The percentage of both group A and group B was $100 \%$. Thus, each group performed in the same way under each input condition. Therefore, for these students, contextual cues that preceded the target clause did not affect the results when compared to the condition in which neutral contexts were provided.

The fact that Group A (with contextual cues) and Group B (with neutral context) performed in the same way under each input condition indicated that the existence or absence of a contextual cue in a sentence does not influence how the participants from advanced proficiency level interpret the 
subject while processing the target sentences. As a result, it can be concluded that the effects of the first noun principle suggested by VanPatten (2007) does not appeal to students from higher proficiency level. When the overall frequency of advanced level students is taken into account, the results revealed that they identified all of the subjects in the target clauses correctly $(100 \%)$. As a consequence, the first hypothesis- contextual cues preceding the target clause will help L2 learners interpret most of the subject correctly, is confirmed for advanced level students. However, the second hypothesis- L2 learners will misinterpret most of the subject when the clause preceding the target one is neutral in terms of its context, is disconfirmed because all of the responses were accurate.

The same responses of the two groups can be due to the fact that students from advanced proficiency level do not depend on every detail, responding automatically by not giving much effort to understand a sentence. Thus, they will probably not differentiate a sentence whether containing a contextual cue or neutral context. Their higher proficiency level will also help them process the input they have received accurately by not paying attention to the context.

\section{Conclusion}

VanPatten and Houston (1998) concluded that the presence of context makes a difference in the interpretation of a sentence. On the other hand, they also noted that future research should investigate if such an assertion holds for different languages. The present study confirms that contextual cues preceding the target clause help L2 learners interpret the subject of a sentence correctly. In addition, it reveals that when such cues do not exist, L2 learners from lower proficiency level are under the influence of the First Noun Principle. Furthermore, the study suggests that such factors are not necessarily competing with each other when students from higher 
proficiency levels are concerned. This conforms to VanPatten's (2007) assertion that the principles and sub-principles of IP theory may work together, by either interacting or overriding each other. Thus, the present study confirms findings from previous research factors affecting the interpretation of the received input in target sentences among L2 learners. Also, the validity of the psycholinguistic processing strategy discussed in the literature review is supported.

\section{Limitation of the Study}

As discussed earlier, in order to activate learners' schemata and make them gain topic familiarity, the researcher tried to conduct a discussion in English with beginner learners. However, because of their limited language proficiency, the session was very limited when compared to the other group from advanced proficiency level.

\section{Suggestions for Further Studies}

Further studies are needed to better understand the conditions supporting the Contextual Constraint Principle; it may be that not merely preceding context overrides the First Noun Principle, but rather, the mere presence of contextual cues overrides it.

\section{References}

Cadierno, T. (1992). Explicit instruction in grammar: a comparison of input based and output based instruction in second language acquisition. Unpublished doctoral thesis, University of Illinois at Urbana-Champaign.

Cadierno, T. (1995). Formal Instruction from a Processing Perspective: An Investigation into the Spanish Past Tense, The Modern Language Journal, 79: 179-193.

Cantürk, B. (2001). Explicit Grammar Instruction: A Comparison of Comprehension-based and Production-based Instruction for EFL Learners, T.C. Anadolu Üniversitesi Yayınları: No. 1276. Yabancı Diller Yüksekokulu Yayınları: No. 01: Eskişehir. 2001.

Cheng, A. (1995). Grammar instruction and input processing: The acquisition of Spanish ser and estar. Unpublished doctoral thesis, University of Illinois at Urbana-Champaign. 
DeKeyser, R.M. \& Sokalski. (1996). The Differential Role of Comprehension and Production Practice, Language Learning, 46/4: 613-642.

Gass, S. M. \& Schachter, J. (Eds.). (1989). Linguistic perspectives on second language acquisition. Cambridge: Cambridge University Press.

Krashen, S. D. (1985). The input hypothesis. London: Longman.

Larsen-Freeman, D. \& Long, M. H. (1991). An introduction to second language acquisition research. London: Longman.

Lee, J. F. (1987). Morphological factors influencing pronominal reference assignment by learners of Spanish, Studies in Spanish (221-232). Lanham, MD: University Press of America.

Lee, J. F. \& VanPatten, B. (1995). Making Communicative Language Teaching Happen. New York: McGraw-Hill.

Lee, J. F. (2003). Cognitive and Linguistic Perspectives on the Acquisition of Object Pronouns in Spanish as a Second Language. In Barbara Lafford and Rafael Salaberry (Eds.), The Acquisition of Spanish: The State of the Science. Washington, DC: Georgetown University Press.

LoCoco, V. (1987). Learner comprehension of oral and written sentences in German and Spanish: The importance of word order. A research perspective (119-129). Cambridge, MA: Newbury House.

Long, M. H. (1983). Native speaker/non-native speaker conversation and the negotiation of comprehensible input. Applied Linguistics, 4, 126-141.

Paulston, C. B. (1972). Structural pattern drills. Teaching English as a second language. New York: McGraw-Hill.

VanPatten, B. (1984). Learner comprehension of clitic object pronouns in Spanish. Hispanic Linguistics, 1, 56-66.

VanPatten, B. (1996). Input Processing and Grammar Instruction in Second Language Acqquisition. Norwood, N. J: Ablex.

VanPatten, B. (2003). From input to Output: A Teacher's Guide to Second Language Acquisition. Boston: McGraw Hill.

VanPatten, B. (Eds.). (2007). Theories in second language acquisition, An introduction. Mahwah, New Jersey. 
VanPatten, B. \& Cadierno, T. (1993). Explicit Instruction and Input Processing, Studies in Second Language Acquisition, 15: 225-259.

VanPatten, B. \& Houston, T. (1998). Contextual effects in processing L2 input sentences. Spanish Applied Linguistics, 1 (2), 53-70.

VanPatten, B. \& Oikkenon, S. (1996). Explanation versus Structured Input in Processing Instruction, Studies in Second Language Acquisition, 18: 225-243.

VanPatten, B. \& Sanz, C. (1995). From input to output: Processing instruction and communicative tasks. Second Language Acquisition and Pedagogy. Hillsdale, NJ: Erlbaum.

\section{Appendix A}

\section{Sentences with contextual cues for Group A:}

1. Ferhunde feels like a victim when Şevket insults her.

2. Fikret was so happy because Tahsin bought her a present.

3. Şevket doesn't improve himself in his job, but Sedef does, and at times she criticizes him.

4. Oğuz lost his job, so Leyla gave him some money.

5. Hayriye started to cry when Ali Riza told her bad news.

6. Necla was ill, so Cem brought her to hospital.

7. Fikret became sad when Cevriye shouted at her.

8. Ayşe felt excited as Leyla brought a dog.

9. Ali Riza was shocked when Ferhunde laughed at him.

10. Hayriye wanted to change her house, so Cem found a new house.

\section{Sentences with neutral context for Group B:}

1. Ferhunde noticed that Şevket was insulting her.

2. Fikret understood that Tahsin bought her a present.

3. Şevket knows that sometimes Sedef criticizes him.

4. Oğuz told his friends that Leyla gave him some money. 
5. Hayriye realized that Ali Riza was going to tell her bad news.

6. Necla told her family that Cem brought her to hospital.

7. Fikret knew that Cevriye would shout at her.

8. Ayşe guessed that Leyla would bring a dog.

9. Ali Riza thought that Ferhunde laughed at himself.

10. Hayriye heard that Cem found a new house. 